\title{
La definición del concepto del honor. Su entidad como objeto de investigación histórica
}

\author{
Carlos Maiza Ozcoidi
}

Las dificultades inmanentes al estudio de cualquier componente del horizonte mental desplegado entre los participantes de una cultura, dificultades concernientes fundamentalmente al hallazgo de fuentes que aporten testimonios que faculten al historiador para traspasar el velo con el que el pensamiento consciente encubre las expresiones mentales, se acentúan si enfocamos nuestra atención hacia la vivencia del sentimiento del honor. $E$ inconveniente preliminar estriba en la ambivalencia etimológica de dicho concepto, lo que ha provocado cierta indefinición en la acepción del término. La idea del honor permanece intrínsicamente vinculada a la noción de honra; sin embargo, la imprecisión de los contornos que delimitan el espacio conceptual supuestamente ocupado por estos vocablos ha generado una confusión de la que no han logrado liberarse algunos autores que han examinado esta materia, lo que ha propiciado desacuerdos que dimanan con exclusividad de la esencial ambigüedad del concepto.

Encarnación-Irene Serrano considera, amparándose en las definiciones propuestas por el Diccionario de la Real Academia Española, que honor remite a un sentimiento íntimo al individuo, mientras que honra apela a su exteriorización, por lo que afirma que «el honor clásico...está vinculado a los actos externos y es aprecio y respeto que se obtiene por ellos de la sociedad. Es lo que nosotros Ilamaríamos honra en su sentido puro y estricto" '. Sobre esta hipótesis, que presupone una contraposición entre honor y honra con respecto a la dualidad expresada entre la conciencia del propio ser y la imagen reflejada del mismo, subrayaba

Serrano Martinez, E., "Honneur"y "Honor": su significación a través de las literaturas francesa y española (Desde los origenes hasta el siglo xvi). Murcia, Universidad de Murcia, 1956, pág. 30. 
Américo Castro que «el idioma distinguía entre la noción ideal y objetiva del 'honor', y el funcionamiento de esa misma noción, vitalmente realizada en un proceso de vida singularizada. El honor es, pero la honra pertenece a alguien, actúa y se está moviendo en una vida» 2. La abstracción inmaterial que para Castro determina la esencia del honor adquiríía sustantividad al concretarse social, aunque individualmente, en honra. Adoptando una postura antagónica, pese a coincidir en la efectiva diferenciación de significado entre ambas palabras, autores como Rafael Serra Ruiz se decantan por una interpretación inversa a la referida con anterioridad, pues en su obra: Honor, honra e injuria en el Derecho medieval español, respalda la caracterización del honor como irradiación colectiva de una honra personal.

La sutil disimilitud entre los dos términos no implica que la distancia semántica que les separa haya sido observada de manera estricta a través de la historia. Encarnación-Irene Serrano verifica que ya con el advenimiento del Siglo de Oro los escritores españoles y franceses identificaban honor y honra, y que en la literatura precedente las dos expresiones en ocasiones se confundían, y eran empleadas indistintamente, y en otros casos se individualizaba su particularidad de forma voluntaria. En la actualidad, numerosos estudios elaborados por historiadores y antropólogos obvian, consciente o inadvertidamente, la existencia positiva de tales matices, adoptando las dos palabras contenidos equivalentes. En el presente artículo, pese al riesgo de desdibujar su entidad específica, y al hecho de que, como aclararemos con posterioridad, nos proponemos ceñir el análisis, prioritariamente, a la dimensión social del honor, lo que competería a la noción de honra, hemos optado por la utilización exclusiva del término honor con la intención de respetar el lenguaje habitual de las clases populares durante los siglos modernos, época referente de este trabajo, concretamente el XVIII navarro, que aluden, de modo mayoritario, mediante esta única voz a la doble faceta que manifiesta el concepto, relegando honra a la función de esporádico sinónimo.

La condición binaria del honor se concreta, asimismo, en una segunda oposición que acrecienta su complejidad, entorpeciendo considerablemente su conocimiento. Julián Pitt-Rivers advierte de las "dificultades inherentes al análisis del honor, pues es a la vez un sentimiento y un hecho social objetivo, por un lado, un estado moral que se desprende de la imagen que cada uno tiene de sí, y que inspira las acciones más temerarias o 
el rechazo a actuar de una manera vergonzante, sea cual fuere la tentación material; y, al mismo tiempo, un medio de representar el valor moral de los demás: su virtud, su prestigio, su rango, y en consecuencia, su derecho a la prelación» ${ }^{3}$. El honor, concebido como principio cardinal en la pugna por la obtención de una posición que proporcione el disfrute, efectivo o aparente, de prerrogativas que conlleven una diferenciación con respecto al común de un grupo social, auspicia una opción interpretativa que ha suscitado, ocasionalmente, una, juzgamos, simplificada formulación del concepto, que estima que «en su sentido más estricto y preciso, el honor requiere algo más que la mera aceptación de las normas sociales establecidas. Depende más bien del logro de superioridad y distinción» ${ }^{4}$. El honor que algunos antropólogos denominan «de precedencia» no cubre, ni remotamente, la dilatada naturaleza de esta noción. Si, en efecto, es incuestionable la intrínseca consonancia entre honor y privilegio, asimilarlos de modo excluyente postergaría a la inmensa mayoría de la población de cualquier colectividad al des-honor. Por el contrario, este estudio pretende concentrarse con particularidad en el examen del honor que hemos acordado designar «de permanencia», aunque no renunciamos a abordar eventualmente el honor de precedencia cuando el curso de la investigación así lo requiera.

\section{PROPIEDADES CONSTITUTIVAS DEL HONOR DE PERMANENCIA}

El desdoblamiento del concepto del honor es sintetizado por Pitt-Rivers al declarar que «el honor como sentimiento y modo de conducta se distingue del honor como calificación para la Lista de Honores» ${ }^{5}$, lo que equivaldría, en principio, a disociar honor de permanencia y de precedencia. Si la consecución del honor de precedencia radica en la posesión, o cuanto menos en el usufructo, de elementos y atributos que encarnen implícitamente una representación de preeminencia y primacía, y cuyo requisito indispensable consiste, por definicićn, en la monopolización de sus rasgos fundamentales por un limitado estrato de población, más o menos amplio, pero siempre minoritario, la circunstancia básica que define el honor de

3 PitT-Rivers, J., «La enfermedad del honor», en Gautheron, M. (ed.), El honor. Madrid, Ed. Cátedra, 1992, pág. 20.

4 ZEID, A., "Honor y vergüenza entre los beduinos de Egipto», en Peristiany, J.C. (Dir.) El concepto del honor en la sociedad mediterránea. Barcelona, Ed. Labor, 1968, pág. 238.

5 PitT-Rivers, J., «Honor y categoría social», en Peristiany, J.G. (dir.), El concepto del honor..., op. cit., pág. 23. 
permanencia reside en su difusión general, pues se presupone consustancial a todo individuo, independientemente de su condición social. No obstante, es preciso graduar con exactitud el verdadero alcance de su virtual universalidad.

El carácter transcendente del honor entraña una evidente capacidad hereditaria, pues «el honor pertenecía in solidum a la familia o al linaje propiamente dichos y era transmitido de una generación a otra como un legado colectivo; podía verse aumentado o reducido por los miembros individuales, hombres o mujeres, por medio de su conducta loable o vergonzosa» 6 . La convicción, extendida de manera uniforme por todos los estamentos de la sociedad, en la patente materialidad de un determinismo genético implanta un rígido sistema de creencias cimentado en la certidumbre de una transferencia biológica, de padres a hijos, de pautas de comportamiento; como estima Domínguez Ortiz en referencia a la actitud de las capas no privilegiadas, «el sentir popular se pronunciaba sin titubeos en pro de la índole hereditaria de las buenas y malas cualidades» ${ }^{\text {? }}$. La inevitable disposición a reincidir en la manifestación personal de un repertorio de vicios y virtudes determinados genéticamente induce a la ampliación subjetiva del dominio jurídicamente asignado al influjo de este fatalismo biológico. Sus efectos no se circunscriben de modo absoluto a colectivos infamados mediante argumentos étnicos o religiosos, o a sujetos estigmatizados por razón del oficio ejercido por su familia, sino que incumben potencialmente a todo individuo. La tendencia indefectible a reproducir unas normas de conducta heredadas proinueve que el honor o deshonor, parcialmente a ella asociado, que la comunidad reconoce a la persona entronque de forma ineludible con el honor o deshonor de sus ascendientes.

El honor de permanencia denota la adquisición del cupo mínimo de honor imprescindible para afianzarse en el seno de una colectividad social, y deriva de la participación en una estructura ideológica compartida y del acatamiento de una serie de valores imperantes. Si el honor de precedencia conforma una percepción del entramado social afirmada sobre la certeza de una manifiesta desigualdad honorífica jerarquizada, aunque no se plasme linealmente, ya que se evidencia una compleja fragmentación en múltiples espacios, yuxtapuestos y no superpuestos, que se engarzan entre

6 DI BELLA, M.P., «El nombre, la sangre y los milagros: derecho al renombre en la Sicilia tradicional», en PITT-RIVERS, J. y Peristiany, J.G. (eds), Honor y gracia. Madrid, Alianza Universidad, 1993, pág. 201-202.

7 Dominguez Ortiz, A., Las clases privilegiadas en el Antiguo Régimen. Madrid, Ed. Istmo, 1985, pág. 187. 
sí, el honor de permanencia establece una fractura dicotómica que «divide a los miembros de la sociedad en dos categorías fundamentales, la de los dotados de honor y la de los privados de él» ${ }^{8}$. Si el honor de precedencia consiente una significativa movilidad orientada en distintas direcciones, la transición entre honor de permanencia y deshonor no es gradual; no existe punto medio. La oposición honor-deshonor se descompone en una intrincada organización de variables binarias antitéticas. La cuestión no se plantea en términos de incremento o disminución de honor, sino de integración o marginalidad e, inclusive, de exclusión, si deslindamos ambos conceptos como distingue Jean-Claude Schmitt: "marginalidad, que implica un estatuto más o menos formal en el seno de la sociedad y expresa una situación que, en teoría al menos puede ser transitoria...(y) la noción de exclusión, que señala una ruptura - a veces ritualizada - con relación al cuerpo social» ${ }^{9}$. Esta dimensión del honor, que se otorga merced a la ausencia de cualquier nota de ignominia, garantiza el respeto a los derechos habitualmente reconocidos a un individuo común en el interior de su comunidad.

La brecha entre ambas concepciones del honor no impone su desconexión categórica; la estrecha vinculación entre los dos horizontes de este mismo concepto diluye, en ocasiones, su especificidad. Los factores constitutivos del honor de precedencia adquieren coyunturalmente, a causa de su inherente función singularizadora, el cometido de actuar como elemento del honor de permanencia. Así, el goce de la hidalguía confiere una situación de privilegio en la escala honorífica, aunque, es obvio, no posibilite forzosamente prerrogativas de naturaleza económica o política; sin embargo, en zonas donde prevalece la hidalguía universal tal carácter diferenciador se desvanece. La relatividad de los principios que configuran el honor no supone la única revelación de la calidad interdependiente de su doble fisonomía. El honor de precedencia no secciona, como hacía el de permanencia, la sociedad en dos fracciones exentas. Los sujetos que aspiren a conquistar un puesto relevante en la gradación de honores continúan comprometidos a acatar los preceptos que modelan el honor de permanencia, por lo que «ninguna persona es aceptable, cualesquiera que sean su posición social y sus realizaciones, si está falta de los componentes del honor...su deficiencia abre el camino de la descalificación social» ${ }^{10}$. La deshonra neutraliza las ambiciones

8 Peristiany, J.G., Introducción a Peristiany, J.G. (dir.), El concepto del honor..., op. cit., pág. 12.

9 SchmitT, J.C., voz «La historia de los marginados», en Diccionario del saber moderno. La nueva historia. Bilbao, Ed. Mensajero, 1988, pág. 403.

10 Peristiany, J.G., Introducción a Peristiany, J.G. (dir.), El concepto del honor..., op. cit., pág. 12. 
honoríficas, pues, como lamenta Nicolás de Echalecu, aquéllos que le han imputado hacer cebedon, cesión de bienes, «no ttan solamentte tiran a perderle el créditto y esttimación sino tambien a dejarlo imposibilittado para la prettensión de qualquier genero de estado o acomodo que corresponda a un hombre de esttimación» ${ }^{11}$. El acceso al honor de precedencia exige como premisa inexcusable la obtención del honor de permanencia. Es la carencia de éste la que provoca el deshonor y no la privación del honor de precedencia. No coincidimos con la teoría defendida por José Antonio Maravall al suponer que «a medida que se alejan del rey las restantes capas, el reflejo del honor que les llega es más débil, hasta llegar a desaparecer, y cuando desaparece se produce esa falta de honor, esa tacha por deshonor» 12. La fractura honor-deshonor no cabe en el desarrollo del honor de precedencia.

\section{a. El honor como percepción externa de un sentimiento interno}

Ningún componente de una comunidad, con independencia de su predicamento, se halla exonerado de la posibilidad de un eventual descrédito. Tal contingencia remite a la esencia social del honor, la cual decreta la primacía del reflejo percibido por el grupo sobre la conciencia íntima del propio honor, puesto que «el sentimiento del honor se vive de cara a los demás...la estima de sí mismo, es ante todo el hecho de defender, a cualquie i precio, cierta imagen de sí mismo destinada a los demás" ${ }^{13}$. El concepto del honor encierra la paradoja de encarnar, de modo simultáneo, una vivencia intrínsicamente personal y su manifestación estrictamente social. No obstante, la apreciación del honor de un individuo no concierne a éste, sino a la colectividad, que es la que determina el nivel de honor de precedencia y la posesión o no de honor de permanencia. La antinomia constatada por Pitt-Rivers al sostener que «honor es el valor de una persona a sus propios ojos, pero también a ojos de su sociedad" ${ }^{14}$ se resuelve irremediablemente en favor de ésta. Adoptada esta hipótesis, el deshonor sería resultado de una refracción en la imagen de sí emitida por una persona hacia la comunidad, de una distorsión entre el honor sentido y el

Archivo General de Navarra, Procesos, Sarasa, sala 1, 1746, fajo único, núm. 10.

12 Maraval.., J.A., Poder, honor y élites en el siglo XVII. Madrid, Ed. Siglo XX1, 1989, pág. 42.

13 Boundieu, P., «El sentimiento del honor en la sociedad de Cabilia", en Peristiany, J.G. (dir.), El concepto del honor..., op. cit., pág. 189.

14 PITt-Rivers, J., "Honor y categoría social», en Peristiany, J.G. (dir.), El concepto del honor..., op. cit., pág. 22. 
La definición del concepto del honor. Su entidad como objeto de investigación...

honor reflejado. La deshonra, de esta forma, atañe a las dos dimensiones del honor, ya que se genera al no corresponder el honor reconocido por el grupo con el que el individuo juzga ser acreedor, e impedirle, por ello, ejercerlo en su vida cotidiana, ya sea con afán de realzar su presencia o, en busca, sencillamente, de conservar el vínculo indispensable que le permita permanecer en su medio social.

Convenimos con la declaración de Peristiany y Pitt-Rivers respecto a que «el honor es, por una parte, una cuestión de conciencia moral y un sentimiento al mismo tiempo y, por otra parte, un hecho de reputación" ${ }^{15}$. No negamos la irrefutable certeza de la interiorización de los cánones que delinean la concepción del honor, pero sí sostenemos que éste únicamente obtiene validez tras el dictamen favorable del grupo; su sanción externa legitima su sentimiento interno. No consideramos adecuada la diferenciación observada por Marta Madero, en su estudio sobre la injuria en Castilla y León durante la Baja Edad Media, entre honor subjetivo y objetivo, ya que «el aspecto subjetivo del honor debe, sin embargo, entrar en contacto con la realidad, ya que el sentimiento personal que se manifiesta en la conducta será tarde o temprano juzgado por los demás " ${ }^{16}$. La condición del honor como extensión incorpórea del individuo proyectada hacia la sociedad, y su consiguiente percepción por ésta, se concreta lingüísticamente en el vocabulario utilizado en el siglo XVIII, cuando términos como honor y fama ofrecen, con frecuencia, significados semánticos escrupulosamente sinónimos; como aprecia Julio Caro Baroja, «la honra tiene su expresión social en lo que se llama "fama" y la deshonra la tiene en la "infamia"»" 17.

Américo Castro advirtió, ateniéndose al análisis de las obras teatrales de los siglos XVI y XVII, que el honor "no aparece como concepto, sino como dimensión de vida individualmente singularizada» ${ }^{18}$. Este parecer admite una generalización, pues el plano interior constituye un ámbito consustancial al honor hasta el extremo de equiparar con él la idea del propio ser; son corrientes expresiones como las pronunciadas por Juan de Eguilaz al sentirse agraviado, de ser ello «en desdoro de su persona y

\footnotetext{
15 Pitt-Rivers, J., y Peristiany, J.G., Introducción a Pitt-Rivers, J., y Peristiany, J.G. (eds.), Honor y gracia. Madrid, Alianza Editorial, 1993, pág. 21.

i6 Pitt-Rivers, J., «La enfermedad del honor» en Gautheron, M. (ed.), El honor..., op. cit., pág. 21.

17 Caro Baroja, J. op. cit., «Honor y vergüenza», en Peristiany, J.G. (dir.), El concepto del honor..., op. cit., pág. 81.

18 Castro, A., De la Edad..., op. cit., pág. 54.

19 AGN, Procesos, Laurendi, sala 1, 1754, fajo único núm. 23.
} 
esttimacion» ${ }^{19}$, en las que se alude tácitamente al indisociable destino de ambas nociones: existencia y honor. Esta indisolubilidad no queda confinada en el dominio privativo del honor de permanencia, pues afecta, asimismo, al de precedencia; estimamos que la interpretación, formulada entre otros autores por Jack Goody, que propugna una confrontación entre "honor asociado a personas y el honor asociado a funciones y títulos» 20 implanta una distinción ficticia. El disfrute, aun transitorio, de puestos o cargos que otorguen un honor eminente imprime un carácter honorífico que se integra en la propia naturaleza del individuo. El ejercicio, por ejemplo, de los empleos de gobierno u "oficios de república», fundamentalmente la alcaldía y la regiduría, que en el siglo XVIII navarro representan, en la inmensa mayoría de las comunidades, el único medio de acceder a un honor de precedencia que podríamos denominar «de gestión política», y que, significativamente, son designados como «cargos honoríficos», no proporciona un honor cuya vigencia se limite al período preciso de ocupación de los referidos empleos, sino que se incorpora de modo permanente a su persona. El honor de precedencia no se adhiere a un sujeto, no simboliza un revestimiento externo; por el contrario, se confunde en un todo compacto.

Sin embargo, en la cuestión del honor prevalece siempre el vigor de la facultad coactiva del grupo sobre la coerción interna emanada del individuo, coerción que obedece al deseo de actuar conforme a la imagen interiorizada de sí mismo. En la documentación consultada, básicamente procesos judiciales, sólo en ocasiones excepcionales se apela a la conciencia como fundamento del honor. Esta circunstancia, combinada con la dificultad que reviste la aprehensión de la mentalidad íntima, puesto que, pese a ser el proceso una fuente privilegiada, nuestros informantes, obviamente, se sentirian reticentes a exteriorizar convicciones que pudieran colisionar con la ideología hegemónica en su entorno, fuerza a que cualquier investigación que pretenda reflejar el concepto de honor renuncie a su incuestionable realidad emotiva y moral, y se ciña con exclusividad a su calidad social. La disyuntiva, no obstante, se desvanece si aceptamos el criterio sustentado por Agnes Heller de que «el esquema-base de la moral es la subordinación de las necesidades, deseos, aspiraciones particulares a las exigencias sociales» ${ }^{21}$, con lo que se resuelve la presunta contradicción moral-social del honor.

20 Goody, J., La evolución de la familia y del matrimonio en Europa. Barcelona, Ed. Herder, 1986, pág. 52.

21 Heller, A., Sociología de la vida cotidiana. Barcelona, Ed. Península, 1987, pág. 132. 


\section{b. El honor de permanencia como factor activo en la cotidianidad}

Con anterioridad hemos mencionado que la noción de honor de precedencia entraña un dinamismo del que carece el honor de permanencia. Éste, a diferencia del de precedencia, no contempla la posibilidad de un potencial movimiento ascendente. Ello no implica que la pugna por la consecución de una estimación honorífica se restrinja al campo del honor de precedencia, pues «aun cuando el honor se hereda con el nombre de la familia, debe ser constantemente afirmado y reivindicado» ${ }^{22}$. La voluntad encaminada al logro del honor de permanencia, a pesar de que derive únicamente de un propósito orientado a su custodia y no a un anhelo de incrementarlo, no se caracteriza por una actitud de pasividad. No coincidimos con la afirmación de Abou A.M.Zeid en referencia a que «el honor, en el sentido amplio de la palabra, se considera como asunto de sumisión a las normas tradicionales de conducta. En ese sentido, honor es aproximadamente sinónimo de "bondad" o "virtud". El honor se consigue, o, más exactamente, se mantiene, por la simple y sincera conformidad a las normas sociales imperantes. Ésta es una forma más bien pasiva de adquirir honor" ${ }^{23}$. Además de entender como excesivamente reductiva la identificación del honor de permanencia con las virtudes morales y de comportamiento, ya que se vincula también con otros factores de raigambre rigurosamente social, juzgamos que, pese a su virtual posesión por toda persona, para su preservación es indispensable su constante ratificación en la vida cotidiana mediante los gestos, supuestamente, más nimios, como atestigua Antonio Romeo al asegurar haber «en ttodos ttiempos procurado conservar su onor en obras, palabras y acciones» 24 .

Si la concesión del honor de precedencia acredita una remuneración simbólica, mas no exenta, usualmente, de recompensas más tangibles, a los vencedores del incruento combate honorífico, ya que "toda sociedad que ha alcanzado un cierto grado de evolución...ha de establecer un sistema de atribuciones y deberes y correlativamente de compensaciones o "retribuciones" por el ejercicio de las diversas actividades en servicio de todo el grupo, que derivan de aquellas funciones» ${ }^{25}$, el honor de permanencia no se muestra indiferente al complejo mecanismo distributivo de apremios,

22 Peristiany, J.G., Introducción a Peristiany, J.G. (dir.), El concepto del honor..., op. cit., pág. 13.

${ }_{23}$ ZEID, A., “Honor y vergüenza entre los beduinos de Egipto", en Peristiany, J.G. (dir.), El concepto del honor..., op. cit., pág. 237.

24 A.G.N., Procesos, Mendíbil, sala 3, 1768, tajo único, núm. 13.

25 Maravall, J.A., Poder, honor y élites... op. cit., pág. 16. 
estímulos y reconocimientos, pues «implica no sólo una preferencia habitual por un determinado modo de conducta, sino la adquisición del derecho a cierto tratamiento como recompensa» ${ }^{26}$. Rechazamos, igualmente, la armonización de la oposición, creemos que artificial, entre honor activo y honor pasivo con el binomio honor masculino-honor femenino; no nos adherimos a la aseveración de Pitt-Rivers en relación a que «mientras que el honor masculino es una cuestión de precedencia, en primer lugar, y el hombre de honor lucha por poner su nombre a la vanguardia de su grupo, el honor de las mujeres es más bien una cuestión de virtud y pureza sexual» ${ }^{27}$. A ambas categorías sexuales atañe, indistintamente, el empeño, activo y diario, por adquirir el beneplácito de su comunidad. Sí concordamos, en cambio, con la hipótesis de la exclusión de la mujer de la lucha por el honor de precedencia, pues sólo le es factible obtenerlo merced al reflejo diferido del honor incorporado al patrimonio honorífico de la familia por sus miembros varones.

\section{EL HONOR: UNA REALIDAD EMOTIVA DE TRANSCENDENCIA SOCIAL}

El estudio de cualquier aspecto concerniente al universo mental conlleva el riesgo de concebir éste en su dimensión exclusivamente emotiva e inmaterial, omitiendo, en consecuencia, el nexo que le vincula con los diversos elementos condicionantes, igual de reales, pero quizás más evidentes, que lo configuran. La historia de las mentalidades, como denuncia François Dosse, «a menudo... se contenta con transcribir la evolución de las representaciones, la manera como las gentes perciben su época, sin preocuparse de establecer una relación cualquiera entre estas representaciones y aquello que, en lo real, las ha suscitado" ${ }^{28}$. En el caso concreto del honor su esencia emocional no anula su naturaleza social; la definición que subestimara esta faceta mutilaría de modo irremediable su complejidad. La imposibilidad de conceptuar el honor como materialidad apta para ser percibida en términos cuantitativos o, inclusive, estrictamente narrativos, no debe inducir a valorarlo en función de su hipotética identidad como mera abstracción susceptible, como tal, de transplantarse de una a otra cultura

26 PITt-RIVERS, J., «Honor y categoría social», en Peristiany, J.G. (dir.), El concepto del honor, op. cit., pág. 22

${ }_{27}$ Id., "El lugar de la gracia en la antropología», en Pitt-Rivers, J., y Peristiany, J.G. (eds.), Honor y gracia... op. cit., pág. 295.

${ }_{28}$ Dosse, F., La historia en migajas. Valencia, Ed. Alfonso el Magnànim, 1988, pág. 210. 
sin sufrir mutación alguna. El honor no es una entelequia etérea producto de la mente, gestada por ésta con independencia de las imposiciones del mundo «sensible»; es preciso evitar «una historia de las mentalidades concebida con un fin en sí, sin referencia a las solicitaciones de la historia de las estructuras sociales ni de la coyuntura económica» ${ }^{29}$.

El concepto del honor recaba sustantividad al plasmarse en la vida cotidiana, no cumpliendo una función estética ni suntuaria, sino fundamentalmente práctica; no se ostenta, se ejerce, pues, como sostiene Bartolomé Clavero, "es la honra un principio simbólico y efectivo» ${ }^{30}$ simultáneamente. Su evocación nebulosa y difuminada se perfila con mayor nitidez, impregnándose de corporeidad, al utilizarse en todos los órdenes de las relaciones interpersonales generadas en el seno de una comunidad. El honor abandona el excelso ámbito de la moral e irrumpe en el común quehacer diario, ya que "se trata no de una virtud, sino un papel social» ${ }^{31}$. A pesar de la irrebatible especificidad de las mentalidades suscribimos la contrariedad de M.Vovelle ante «la afirmación de la autonomía de lo mental y su irreductibilidad a lo económico y a lo social» ${ }^{32}$.

\section{a. El rechazo del arquetipo del honor como invariable histórica}

La manifiesta ralentización en la transformación de los parámetros que determinan el «imaginario colectivo» puede resultar engañosa y derivar en una inexacta formulación de sus propiedades cimentada en su ficticia inmutabilidad. El tiempo propio del conocimiento histórico, por muy premioso que se revele, no se corresponde con el tiempo peculiar de disciplinas afines, como la sociología y la antropología. La historia de las mentalidades no se inscribe en la intemporalidad que se achaca a los antropólogos ni en el marco de un obsesivo presente que se recrimina a los sociólogos. Aunque para lograr advertir insignificantes inflexiones en el desarrollo de lo mental colectivo es imprescindible recurrir a efectuar su examen en el dominio de la «larga duración», por apremio de su referida estabilidad, ello dista sustancialmente de una evaluación de las mentalidades como indicios que evidencien la existencia de constantes históricas asociadas al comportamiento humano; como declara Vovelle "corremos el riesgo de

\footnotetext{
29 Vovelle, M., Ideologías y mentalidades. Barcelona, Ed. Ariel, 1985, pág. 267.

30 Clavero, B., «Delito y pecado", en Tomás Y VALIENTE, F. y otros, Sexo barroco y otras transgresiones premodernas. Madrid, Alianza Editorial, 1990, pág. 80 .

31 Maravall, J.A., Poder, honor y élites..., op. cit., pág. 60.

32 Vovelle, M., Ideologías..., op. cit., pág. 16.
} 
chocar con el tema de la "historia inmóvil"...y también de encontrarnos en ese nivel en que el tiempo del historiador se confunde con el del antropólogo, para volver a hallar esas nociones que atraviesan la historia sin cambiar, esos "invariables"...(siendo necesario) aplicar una lectura histórica a este tipo de fenómenos» ${ }^{33}$.

Pese a las cuantiosas ventajas que reporta la consulta de obras ajenas a la historia, primordialmente al proveernos de un bagaje conceptual del que, al menos en lo alusivo al honor y cuestiones a él atingentes, adolece la historiografía, la metodología debe responder a un planteamiento plenamente histórico. Aun asumiendo la propensión sociológica a trabajar a nivel de estructuras, apropiándonos de la definición de Krzysztof Pomian, para quien «una estructura no es solamente un conjunto coherente de elementos en el que la transformación de uno solo provoca más tarde o más temprano la del resto,...sólo le interesa (al historiador) si satisface también otras condiciones. En concreto, tiene que mantenerse durante un período multisecular, tiene que ser un período de larga duración » ${ }^{34}$, no debe rehusarse captar la variación, procurando combinar, reproduciendo a Peter Burke, «el agudo sentido para la estructura del sociólogo con el igualmente agudo sentido para el cambio del historiador" ${ }^{35}$, pues desestimamos la opción de adoptar su habitualmente reprochada tendencia a la construcción de modelos excesivamente generalizadores, de abstracciones que desdeñan la potencial presencia de particularidades espaciales y cronológicas. Asimismo, creemos preciso renunciar a la propuesta, ofertada por la antropologia, de proceder mediante formulaciones ideales, ya que la pretensión del historiador se circunscribiría con exclusividad a considerar la vivencia del honor acotada en un espacio delimitado, y en un tiempo definido, desistiendo, por otra parte, de realizar una cuantificación de su intensidad emotiva, estimamos que imposible de graduar con un mínimo de rigor, y ubicarla en una imaginaria escala honorífica jerarquizada por regiones. La previa e inexcusable labor encaminada a descomponer la múltiple realidad histórica no se traduce eri una segregación de los infinitos factores en ella integrados, sino que, inversamente, exige la posterior contextualización del objeto de estudio en función de las dos variables que, al actuar en sincronía, singularizan la investigación histórica: espacio y tiempo.

Como expresa Carlo Ginzburg, en referencia a la aceptación de una teórica inalterabilidad de ciertas manifestaciones de un espíritu humano

33 VOLLeVE, M., op. cit, págs. 252-253.

34 POMIAN, K., VOZ "La historia de las estructuras" del Diccionario..., pág. 198.

35 BuRkE, P., Sociología e historia, ... op. cit, pág. 33. 
indiferente a las circunstancias intransferibles y diferenciadoras de cada cultura, "esta continuidad, rastreable no obstante sus innumerables variaciones, no puede ser reducida en términos generales, a una tendencia del espíritu humano" ${ }^{36}$. Por lo tanto, la finalidad no puede estribar en discernir si el sentimiento del honor es inherente a la condición humana o, por el contrario, emana de la interacción de determinados condicionamientos sociales en una coyuntura propicia para su eclosión, ni en deducir si es innato o adquirido. $\mathrm{Si}$, como reflexiona Norbert Elias, "el espíritu humano tiene unas leyes propias a las que cabe considerar como "naturales" y en el marco de las cuales se da el proceso histórico, al que aquéllas abren el campo e imponen límites...la tarea consiste en determinar con mayor exactitud la variabilidad de la vida y el comportamiento humanos por medio de los procesos históricos. En todo caso, resulta visible cómo los procesos natural e histórico actúan inseparablemente el uno del otro" ${ }^{37}$, el propósito del historiador no se orienta hacia la indagación de los determinismos inmanentes al hombre que supeditan su conducta a unos supuestos principios fijos y universales, sino que se ciñe al análisis de las modificaciones que dichas directrices experimentan en relación a la idiosincrasia de cada sociedad y al examen de la evolución de su imagen por ésta sustentada. En caso contrario, la historia invadiría el terreno privativo de los etólogos.

La labor del historiador no debe encaminarse a polemizar sobre la verosimilitud de que el honor sea o no un rasgo arquetípico consustancial a la naturaleza humana y decantarse, subsiguientemente, por alguna de las alternativas, tal y como resuelve intentar Jacinto Martín Rodríguez, quien, pese a consentir en la incidencia de «matices accidentales», afirma categóricamente que «su esencia será fundamentalmente la misma, obedeciendo siempre a un instinto natural que lleva al hombre al aprecio y estima de su dignidad personal» ${ }^{38}$. El punto de partida radica en la conformidad con respecto a la objetiva sujección de la noción del honor a alteraciones, en su negación como invariable identificable a través del tiempo y del espacio, a pesar de que, ocasionalmente, sea legítimo sospechar la existencia de elementos básicos, pero puntuales, compartidos por culturas dispares. La especificidad de una determinada concepción del honor compete de modo indefectible a la conjunción concreta de dos coordenadas espacial y cronológicamente dadas.

\footnotetext{
36 GinzBurg, C., Mitos, emblemas, indicios. Morfologia e Historia. Barcelona, Ed. Gedisa, 1989, pág. 9, 16.

${ }_{37}$ Elias, N., El proceso de la civilización. Investigaciones sociogenéticas y psicogenéticas. Madrid, Fondo de Cultura Económica, 1988, pág. 200.

38 Martín Rodriguez, J., El honor y la injuria en el Fuero de Vizcaya. Bilbao, Diputación de Vizcaya, 1973, pág. 5.
} 
La distorsión que, juzgamos, pudiera suscitar un talante conciliador hacia actitudes que propugnaran una interpretación del honor como resultado tipificado de la actividad espiritual del hombre, implicaría su inevitable estandarización. Contra esta homogeneización se rebelan Peristiany y PittRivers al reputar como error el «considerar el honor como un concepto constante y único más que como un campo conceptual dentro del cual la gente encuentra la manera de expresar su amor propio o su estima por los demás" ${ }^{39}$. Si al desarrollar sus propiedades constitutivas reseñábamos que la oposición honor de permanencia-deshonor secciona el cuerpo social de forma tajante, sin tolerar graduaciones ni escalonamientos, ello no supone que la línea que delimita los dos campos de esta escisión excluyente no refleje fluctuaciones contingentes que delaten el carácter relativo de la noción de honor, que, como puede atestiguarse en la declaración del Consejo Real de Navarra, restringida a la polémica de los oficios viles, que transcribimos, era percibido con claridad, pues sostiene que «la estimación y concepto común son los que califican el mérito de un oficio y por consiguiente mudan de calidad según el diferente modo de pensar que produce el tiempo y el diverso modo de gobierno que exige la distinción de circunstancias» ${ }^{40}$.

\section{b. La contextualización del honor en la materialidad histórica}

Con anterioridad hemos mencionado la conveniencia de integrar el examen de las actitudes mentales en el contexto global de la sociedad en la que éstas afloran; otorgarles una condición autárquica ilimitada reduciría su entidad a la categoría de entelequia no susceptible de ser analizada históricamente. Como reconoce G.Duby, ciertas obras inscritas en la corriente de la historia de las mentalidades "se han visto llevadas algunas veces a alejarse de lo concreto, a atribuir a las estructuras mentales una autonomía demasiado profunda con respecto a las estructuras materiales que las determinan" ${ }^{41}$. El desprecio de los imperativos sociales que actúan sobre el individuo y contribuyen a formar su paradigma mental induce a la elaboración de modelos ideales extrapolables

39 Pitt-Rivers, J. y Peristiany, J.G., en la introducción a Pitt-Rivers, J. y Peristiany, J.G. (eds), Honor y gracia..., op. cit., pág. 20.

40 AGN, Papeles varios del Consejo Real, Expedientes personales de Farmacéuticos, leg. 10, núm. 455.

41 DuBY, G., Historia social e ideología de las sociedades. Barcelona, Ed. Anagrama, 1976, pág. 9. 
de vigencia pretendidamente universal y, como tales, de equívocia validez. La indisociabilidad del horizonte mental en relación a la totalidad social es corroborada aun por autores extraños, al menos doctrinalmente, a la «nueva historia»; así, José Antonio Maravall certifica que «un elemento ideológico es un factor estructural y pertenece al mundo de lo real, con la misma condición que los que se llamaban factores materiales. En consecuencia, reivindico el derecho de cualquier cultivador de historia social provisionalmente, se entiende, o artificialmente...a abstraer un factor ideológico para convertirlo en objeto de su investigación. Claro que al exponer el desarrollo de su trabajo deberá...tener cuidado de hacerlo de forma tal que siempre aquél se pueda articular con los otros factores ${ }^{42}$. Si la complejidad histórica no se resume en la yuxtaposición de sistemas parciales exentos e inconexos, la mentalidad no representa una excepción; no encarna el papel de compartimento estanco, de oasis aislado definido por su autosuficiencia y exonerado de injerencias externas.

La fluida circulación de influencias mutuas no se reserva al mundo perceptible, mientras que lo mental permanece confinado en una imaginaria cápsula herméticamente cerrada a influjos ajenos a su exclusiva realidad, capaz de engendrar y reproducir, por y para sí, una existencia «que obedece a ritmos y causalidades propias...aparentemente independiente de todo determinismo" ${ }^{43}$. La organización de los esquemas mentales dimana de la intrincada interdependencia de fenómenos de variada índole. El acercamiento al código de normas que prescriben las leyes del comportamiento humano no debe efectuarse sin atender paralelamente a la diversidad de elementos que las moldean. La mentalidad resulta de la mediación simultánea de factores heterogéneos que no intervienen sólo desde una sucesión diacrónica, sino que es indispensable apreciarlos, amparados en criterios sociológicos, desde una perspectiva sincrónica. Su multiplicidad fuerza a rechazar la ilusoria idoneidad de la explicación que abogara por una causalidad simple y a inclinarse por la reciprocidad de las relaciones y dependencias. Duby refiere que «resignados a no poder obtener más que verdades muy parciales y relativas, y obligados a la reserva por esta misma convicción, los historiadores se convencen de la indisociable globalidad de las influencias. Les parece totalmente inútil

42 MaraVAlL, J.A., «Espíritu burgués y principio de interés personal en la llustración española", en Maravall, J.A., Estudios de la historia del pensamiento español. Siglo xVIII. Madrid, Ed. Mondadori, 1991, pág. 245.

43 Vovelle, M., Ideologías..., op. cit., pág. 16. 
empeñarse en ajustar los eslabones de una cadena de causas y efectos. Su esfuerzo consiste en penetrar en las sutilezas de un juego de correlaciones, de «interconexiones» ${ }^{44}$.

El estudio del honor, obviamente, se somete a los requisitos aludidos, ya que se evidencia inexcusable su fusión en la compleja red de intercambios suscitados entre las diferentes estructuras que componen el dilatado panorama de toda cultura. Una parte importante de los inconvenientes que entorpecen su investigación surgen, precisamente, de la infinidad de variables, circunstanciales y mudables, que convergen en su conformación. Por consiguiente, la versatilidad del concepto del honor aparece intrínsicamente ligada al carácter mutable de los vínculos establecidos. Su particular caracterización está condicionada por la singular intersección de los elementos que en ella incidan; su concepción fluctúa en correspondencia a la variabilidad de éstos, por lo que uha de admitirse que cada época vive y concibe un honor distinto, no sólo como sentimiento individual...sino como creencia colectiva y que en tal honor influyen los más variados conceptos sociales» ${ }^{45}$. Suscribir la hipótesis de la inmutabilidad del honor conllevaría, implícitamente, aceptar la estabilidad absoluta de los sistemas de valores y de los múltiples parámetros que definen una sociedad y, por otra parte, ignorar los condicionamientos estructurales condenaría a esbozar una caricaturizada y fosilizada imagen de eficacia ingenuamente universal. Prescindir de su vinculación con los factores "materiales" imposibilitaría reparar en el «juego relativo que existe entre las condiciones de existencia de los hombres y la manera en que reaccionan respecto de ellas ${ }^{46}$.

Sin embargo, los perfiles indeterminados de la noción de honor reclaman una tarea preliminar que delimite, en la medida de lo posible, su ámbito de recíprocas conexiones. El empleo de procesos por palabras de injuria como fuente predominante concede la eventualidad de concretar los principios fundamentales que mayor transcendencia adquieren en su constitución. La potencial capacidad de la injuria como reveladora de una situación social reside en que «tiene la forma de una metáfora que cifra, condensado, un sistema de valores que se expresa invertido. La injuria

44 DuBY, G., “Orientaciones de las investigaciones históricas en Francia. 1950-1980», en Duby, G., El amor en la Edad Media y otros ensayos. Madrid, E. Alianza Universidad, 1990, pág. 217.

45 Serra Ruiz, R., Honor, honra e injuria en el Derecho Medieval Español, Dep. Historia del Derecho, Universidad de Murcia, Murcia, 1969, pág. 15.

46 Vovelte, M., Ideologias..., pág. 92. 
es una metáfora social» ${ }^{47}$. Con ello no insinuamos que el planteamiento de una investigación sobre este tema pueda responder a una valoración del honor «en negativo», puesto que presupondría refutar la multiplicidad de secuencias temporales que conviven en un mismo período histórico y obviar, asimismo, la incuestionable proclividad de las mentalidades a la inercia con respecto al ritmo de evolución de los demás planos que lo integran, por lo que no cumpliríamos con la función reservada al historiador, que «consiste...en confrontar sin parar las diversas temporalidades y en evidenciar los desfases, las discordancias entre realidad social y representación ideológica, que no evolucionan en perfecta sincronía» ${ }^{48}$. Su marcada resistencia al cambio explica que a una transformación en las estructuras materiales, con independencia de su intensidad, no se deduzca necesariamente una transformación en las estructuras mentales. La mentalidad, en el caso que nos ocupa exteriorizada merced a la injuria, que como sostiene Marta Madero, «ignora las mutaciones bruscas» ${ }^{49}$, subyace, indiferente, a la sucesión de acontecimientos y coyunturas. La injuria se manifiesta como una fórmula lingüística que posee la facultad de conservar su carga denigrativa tras la desaparición de las circunstancias históricas que justificaron su implantación en el lenguaje, motivo por el cual nos hallamos incapacitados para establecer un encadenamiento directo del orden: contexto social-concepto del honor-tipo de injuria. Sin discrepar terminantemente, juzgamos pertinente matizar postulados como el expuesto por Martín Rodríguez al declarar que «el honor es un valor social de carácter relativo, que varía con el paso de las generaciones. Así, de la variabilidad histórica del concepto que se tenga del honor depende la mutabilidad temporal de la injuria» ${ }^{50}$.

El desajuste de la injuria en el tiempo, al ser trasplantada a una cultura en la que su coherencia en relación a la realidad social se ve deteriorada, no supone una merma de su efectividad. Su conversión en anacronismo, refugio de recuerdos inconscientes y residuales, no debilita su operatividad cotidiana. Finalizando el siglo XVIII, en 1799, el presbítero beneficiado de la iglesia parroquial de Goizueta, D. Juan Martín de Minondo, reconoce que a aquéllos que se tilda de agotes «se tiene por gentte despreciable, o desesttimada...(aunque) sin embargo de ser ofensiba la

\footnotetext{
47 Madero, M., Manos violentas, palabras vedadas. La injuria en Castilla y León (siglos XIII-XV). Madrid, Ed. Taurus, 1992, pág. 21.

48 Dosse, F., La historia en migajas..., op. cit., pág. 222.

49 Madero, M., Manos violentas, palabras vedadas..., op. cit., pág. 21.

so Martín Rodriguez, J., El honor y la injuria... op. cit., pág. 22.
} 
espresión de agotte nunca ha savido todavía la verdadera significazion e intteligencia que en si encierra esa palabra» ${ }^{51}$. Su vigor connotativo sobrevive a la desaparición de su acepción denotativa. Pese a sus carencias, que inducen a mantener una actitud permanentemente crítica, el proceso por palabras de injuria y el examen de ésta permite una, estimamos, significativa aproximación que facilite, como defiende Jacques Le Goff, «la identificación de los valores de la sociedad y del funcionamiento de las relaciones entre categorías y miembros de esa misma sociedad» 52 .

Que la concreción del honor de una época específica no corresponda de manera escrupulosa al resultado de la interacción de las diversas estructuras con él coexistentes, por efecto de la activa interferencia de vestigios del pasado profundamente sedimentados en la memoria colectiva, no implica que su conformación no se someta, de forma dominante aunque no exclusiva, a la intervención conjunta de dichas estructuras.

Creemos incorrecto abstraer cualquiera de los elementos coadyuvantes con el propósito de proponer una interpretación unilateral, pues de ello derivaría una frustrada, por parcial y fragmentaria, evaluación del honor. Los factores que sobre éste gravitan no ejercen su influjo de modo aislado, sino que se conjugan, superponen y entrecruzan. Algunos autores han concentrado abusivamente la entidad del honor en función de influencias puntuales, cercenando así su complejidad. Américo Castro cimentó su ya citada obra De la Edad Conflictiva en la presunción de que la raíz del honor de los siglos XVI y XVII descansaba exclusivamente en el sistema de limpieza de sangre vigente; Alfonso García Valdecasas aducía, en su tratado sobre su concepción en la clase hidalga, que «el honor español residía, fundamentalmente, en la mujer: en su pudor, honestidad y virtud. $Y$ residía en ella tanto su honor como el del hombre" ${ }^{53}$. Consideramos que supuestos tan restrictivos están mediatizados por la naturaleza de las fuentes consultadas, comúnmente circunscritas al ámbito jurídico y literario, que emiten, por sus propias características, una imagen distorsionada del honor. Estudios como el de Oostendorp, que asimila, con ánimo discriminatorio, el sentimiento del honor a la estrategia matrimonial ${ }^{54}$, ya habían sido rebatidos de antemano por Ramón Menéndez Pidal, quien

\footnotetext{
AGN, Procesos, Huarte, sala 1, 1799, iajo 2 núm. 15.

2 LE GOFF, J., Introducción a Madero, M., Manos violentas, palabras vedadas..., op. cit., pág. 11.

53 Garcia Valdecasas, A., El hidalgo y el honor. Madrid, Revista de Occidente, 1958, pág.

54 OOSTENDORP, H., Th., El conflicto entre el honor y el amor en la Literatura española hasta el siglo XVII. Instituto de estudios hispánicos, portugueses e iberoamericanos de la Universidad estatal de Utrecht, La Haya, 1962.
} 155. 
reprobaba formulaciones similares al lamentar que «el sentimiento del honor se ha estudiado muy limitadamente, contrayéndolo al honor marital» ${ }^{55}$. Un talante tendente, consciente o involuntariamente, a omitir la pluralidad de variables que afectan a la materialización de cualquier exponente del universo mental impediría que las mentalidades se convirtieran «en la prolongación natural y el punto final de toda historia social» ${ }^{56}$.

55 Menéndez Pidal, R., De Cervantes y Lope de Vega. Buenos Aires, Ed. Espasa-Calpe, 1940, pág. 180.

56 Vovelle, M., ldeologías..., op. cit., pág. 19. 